\title{
Effects of Urban Regeneration on the Changing Housing Structures in South Korea
}

\author{
Doil Kim \\ Senior Manager (PhD): NHUF Division, Korea Housing \& Urban Guarantee Corporation \\ Email: kdi@khug.or.kr
}

\begin{abstract}
Acknowledgement
A research work becomes a reality with some form of support and assistance from many people. I extend my sincere gratitude to my lecturers for their support and guidance. I also thank them for their patience, motivation, enthusiasm and immense knowledge that their shared with me on my topic of research, "The effects of Urban Regeneration on the Changing Housing Structure" I extent my appreciation too to my friends and family members for always being there for me, I appreciate their love and gratitude. I thank my University for allowing me to use library resources and making references during my research work. I thank everyone whose contribution has led to the completion of the research. Above all, I am grateful to God for His guidance.
\end{abstract}

\begin{abstract}
Background: The study explored the history of South Korean housing and urban development with focus on a number of changes that have since taken place after major urban regeneration projects. The objective is to discover some of the factors behind the successes of Urban Regeneration and the National Housing and Urban Fund (NHUF) in South Korea. In the end, the impacts of NHUF are discussed with their links to various housing projects, particularly apartments.

Objectives: The key research objectives include investigating how urban regeneration affected and changed the housing structures in South Korea, the changes that have come about as a result of Urban Regeneration in South Korea, the role of NHUF on the implementation of urban regeneration project in South Korea, the challenges faced by NHUF, and new ways of improving urban housing.

Research Design: The study used a mixed method of data collection. Both qualitative and quantitative methods were applied to systematically integrate data on the history of South Korean housing and urban development.

Setting and location: Republic of Korea

Results: The systematic reading of the regulatory plan indicated a clear divide between the central urban areas found within the municipality and the marginal that are not found within the municipality. The results indicate that from the center of the city moving outwards, the good conditions tend to slowly fade, creating room for deteriorated areas. There is also a difference based on the characteristics of the population of the cities concerned. The distribution is also based on the level of education. A higher percentage represents elementary qualifications or those without degree while lower percentages of inhabitant represent those with high levels of qualifications.

Conclusion: In conclusion, it is evident that for successful urban regeneration in South Korea, the element of planning such as sustainability, urban simulation, and local identity need to be put into consideration in areas where regeneration has to be carried out. The paradigm that has emerged based on the demands of each age is determined according to the level of acceptance as well as the executions of the demands of the prevailing circumstances and time. The manner in which regeneration is realized in each region should always be diverse. The strategy of urban regeneration should therefore be considered in South Korea.

Recommendations: There is need for South Korean cities to have multi-stakeholder systems to be able to adequately prepare and market their economy both locally and globally. Agencies need to collaborate to be able to develop and promote and develop the country. The national government should recognize the significance of the local communities in the process of urban regeneration.
\end{abstract}

Keywords: Land Use Planning, Urban Regeneration, Housing Redevelopment, Environment Readjustment

DOI: $10.7176 / \mathrm{JHMN} / 89-05$

Publication date:May $31^{\text {st }} 2021$

\section{Introduction}

Urban regeneration in South Korea is all about refurbishing new projects, housing redevelopment, environment readjustment and many other projects aimed at improving the housing standards. The reconstruction of urban regeneration in South Korea began in the 1950s, after the Korean War. Residential homes, infrastructure, building development were among the projects aimed at social change (Wolfram, 2019). Urban regeneration is directly linked to land use using different mechanisms. More important to note is that land use determines the environmental, socio-economic and health outcomes. Therefore, how a nation is governed plays a key role in land use and urban regeneration. This assignment is a research paper that discusses urban regeneration and National Housing and Urban Fund (NHUF) in South Korea. 
Globally, housing is one of the main challenges facing urban areas. Owning a house in urban areas to many people is considered a dream come true. The majority of urban areas have unaffordable housing with ideally those that are available being very expensive, squeezed and less spaced. NHUF came about as a way of speeding urban regeneration through and offering affordable housing to citizens. This is possible through advanced technology, social innovation and community outreach. Through this, urban planning laws were revised and better, influential and more achievable guidelines and goals enacted to pave way for the growth of the same (Seo et al, 2019).

\section{Background Information}

South Korea is widely known for its intense and advanced technology that has played an essential role in housing regeneration and urbanization. It is highly ranked on the global map for performance and technology advancement. The Korea Land and Housing Corporation takes charge of developing cities and towns through changing lands into affordable housing thus making proper utilization of land. Korea was colonized by Japan thus the categorization into two, North and South Korea. However, the Korea war followed shortly after with a huge section of buildings, land and properties destroyed. The main aim of the Housing Corporation was to restore the buildings and utilize land that was destroyed following the war (Yoon, 2017). Ultimately, the Korean population was rapidly increasing as, after the war, South Koreans who had migrated from their country and those who had been taken to Japan as slaves started to move back home. According to the history of South Korean housing, by this time, there were very limited decent housing projects except those that state-owned. A majority of South Koreans lived in shanties while others in illegally constructed houses. Therefore, this menace persisted for a long time and the government in a bit to address these challenges stepped up and initiated the housing corporation.

Initially, houses were indecently built to cater to the rapid population and settle South Koreans. However, with time, things developed and houses of bricks were commenced. Walls were built high with bricks mixed with cement. These structures were referred to as Yangok hence paved the way for modern housing. In the 1960s, South Korean leadership and governance changed paving the way for economic growth and development. Through this, South Koreans were able to engage in different forms of businesses including processing and manufacturing raw and finished products thus importing to other countries. This quickly transformed to improved livelihood and standards of living where houses began having modern finishing with floors, plumbing systems, roof tiles, earthware cement and many more. This progressed housing from shanties to modern houses (Ham et al, 2017).

The National Housing and Urban Fund's (NHUF) main role was to deliver stable housing to people. Basically, this was aimed to give cities and urban areas a new life with a view of improving lives through quality housing. The NHUF operates on five techniques which are Targeting cities and urban towns, offering support through loans and diversified investment methods, government budget, financing consumers and exclusive operation institutions. The fund ideally allows private development (Watt et al, 2017).

In the early 2010s, urban regeneration and development were some of the most talked-about projects, with various researches carried around in South Korea. For instance, it was decided and planned that for economic, social, political and cultural aspects to develop, proper land use and regeneration needed to be upheld. This thus introduced South Korean apartments where modern houses came up, saving on space as well as meeting the rapid population growth. Ideally, this did not stop.Citizens were mobilized to come together with Savings and Cooperative Societiesand other funding aids to boost the strategy (Yoon, 2017). First, there was the coordination of government and relevant ministerial such as the land and housing ministry as well as the urban planning ministry. The aim was to meet and accomplish the same goals without contrast that would slow down the process. A brief history and look into the old South Korea decades ago and currently shows immense changes and development that can only be accredited to urban planning and regeneration. One important thing to note, the regions that were considered rural with shanties and slums built all over have now been transformed into modern houses, apartments and tall buildings that meet the dynamic changes. Prices of land have ideally shot up hence owning and affording a piece of land has become quite an expensive task. Therefore, land regeneration in South Korea introduces job creations and employment, housing to cater and settle the increased populations as well as modernity where the old shanties were replaced by new and modern houses. Religion has ideally played a key role in Urban Regeneration. The construction of modern religious centers paved was for urban development. For instance, most residential and commercial buildings had architectural designs that detail professionalism, and modernity with funding received from different sources. These buildings came up and indicated that there is more to be done in terms of development and housing projects.

\section{Problem Statement}

Basically, following the Korean War, buildings and properties had been destroyed reducing the towns and cities into mere slums. The purpose of the Housing City Fund is to raise funds necessary for the efficient 
implementation of the Housing Construction Comprehensive Plan by the government. With the increased population and other factors that slowed population growth, Urban Regeneration was the first step in meeting these needs and rebuilding the nation. The government thus through addressing these needs aimed to create economic stability and a strong foundation for a performing state to be able to meet the budgets and ideally attract investors (Park et al). Unlike initially where land was affordable and owned by individuals, the housing regeneration plan introduced estate investments where houses were built for commercial purposes. This materialized globally with investors from all over the world coming in and play key roles in funding and upscaling buildings. The Urban regeneration plan involved picking up towns and cities known to be hot spots for tourist attraction and filled with natural attraction with refurbishing, development and development. Some of the buildings that came up include Libraries, scientific labs, technological buildings, government offices, museums and Buildings for national archives among others. The consequences of urban regeneration, therefore, included long working hours, proper utilization of lands, full-time jobs and improved infrastructure, roads and houses altogether. Ideally, the NHUF provides for affordable housing although land rates have gone very high in urban areas and cities. Technology has also advanced with the economic, cultural and social factors highly developed.

\section{Objectives of the Study}

The objectives of this research study are to learn the history of South Korean housing and urban development scoping down to the various changes that have since taken place following the Urban Regeneration project. Notably, the livelihood of people has changed over the years with the effects of urbanization and technology taking over and yielding positive results. Secondly, the research will analyze the National Housing and Urban Fund (NHUF) where the advantages and disadvantages will be discussed with the ideal consequences that have been experienced since its introduction outlined. The various changes including modern housing, high employment and new economic capabilities will also be explored with potential success and solutions to failures that have so far been witnessed. The impact of South Korean urban regeneration is massive and goes beyond its borders to its neighbors. Thus, the project has not only been influential in South Korea but also in the neighboring states through investments, creation of job opportunities, affordable housing and settling people due to rapid population growth. Through this research project, I will be able to unmask some of the factors behind the successes of Urban Regeneration and NHUF.

\section{Research Questions}

Some of the research questions on this project are:

- How has Urban Regeneration impacted and changed the housing structures in South Korea?

- What are the changes that have come about as a result of Urban Regeneration in South Korea?

- Some certain advantages and disadvantages have come about as a result of urban regeneration. What are they and how have they been impacted.

- What are the new ways of improving urban housing?

- What is the role of NHUF and how has it impacted the Urban Regeneration project in South Korea?

- What are the challenges faced by NHUF and how can the challenges be addressed?

\section{Justification of the Study}

As the world faces challenges regarding the shortage of land and improper land use, urban regeneration plays a key role in solving some of these challenges. For instance, the world population is rapidly increasing by day leaving very few lands to be owned by human beings. Ideally, this has created increased land rates and owning a house/home is not easily affordable (Kim et al, 2019). The evaluation of housing projects and costs is therefore not an easy task thus NHUF comes to the aid of citizens through offering affordable housing. The results of this project go beyond the South Korean borders due to new and increased economic capabilities that in turn create more opportunities for investors and other projects that give return to the state. Through urban regeneration and NHUF, houses are made affordable and apartments and homes come up to serve and meet the increased population. The data collected from this research will thus not only be used for improvement and creating awareness but also making the wrongs and failures right through inviting new ideas and projects that ideally serve the same goal.

\section{Scope of the Study}

This research study covers the whole region of South Korea with specific attention to urban and rural areas where the analysis of changes in housing will be discussed. Some of the modern buildings in urban areas including iconic libraries, government institutions, scientific laboratories, infrastructure and architecture. Ideally, the impacts of NHUF will be discussed with the links to various housing projects including apartments. Qualitative and quantitative data will be used to carry out the analysis and research methods including interviews, data reviews, questionnaires, observations and secondary data analyzed (Jang et al, 2020). 


\section{Literature Review}

Urban regeneration has created job opportunities in different parts of South Korea. Through urban regeneration, raw and finished materials have been produced with ideally new designs and housing structures creating jobs for both formal and informal sectors. Urban regeneration creates jobs for architects, masons, manufacturers and distributors, artists, painters and many others. According to Kim et al (2020), the popularization of apartments in South Korea was fully adopted in the 1970s. Initially, before liberation, South Koreans were mainly living in small scale multifamily houses. After the war, development and urban regeneration paved way for the construction of modern houses and apartments that did not consume huge parcels of land and ideally served huge crowds of people. The first-ever apartment to be constructed in South Korea after being liberated was referred to as Jongam Apartment. Although the apartment was massive, it was not completely developed with modern finishing as the restrooms were communal and the fittings small. The apartments quickly gained mileage in the 1970s with more improvements coming in with every change. The Mapo Apartment broke boundaries and catered for more people, with approximately 642 units and 6 storey buildings. Changes were instituted from communal washrooms to each household having a separate restroom. Proper and well-fitted finishing, plumbing systems with self-sufficient services. Consequently, the progression was also witnessed in schools and government facilities where all these and a bus stop complex were situated in one area to meet the region's population needs (Kim, 2018). Heated politics took over the constructions and buildings with politicians pledging their support for urban regeneration with affordable housing as part of their agendas. For example, the changes in seasons in Korea played a key role in the development, refurbishing and construction of houses. During the winter season, modern houses were well fitted with floor heating systems, hot water systems under the bedroom floors, radiators and other designs that served and met the season needs. Also, the designs changed progressively from one room serving all the house purposes to the partitioning of bedrooms, living rooms, restrooms and kitchens. Placed at the door was the living room, the kitchen next to the dining room and the restrooms next to the bedroom. Lighting and fixtures ideally advanced with time from single light sources to modernized, multi-purpose that saves on electricity and lighting.

\section{Apartments Popularization}

Online statistics indicate that South Korea is overpopulated with a prediction into the coming years alluding to a house and land crisis (Kang et al, 2020). Specializing in Urban Regeneration is the Korea Housing and Urban Guarantee Corporation (HUG) which basically aims to improve the lives of all South Koreans through affordable housing, Urban renewal, management of housing innovations and implementation of proactive housing policies. HUG works closely under NHUF where cities are transformed through modern housing and development. The expected effects of NHUF have been predicted to positively impact urban regeneration with diversity and improved infrastructure. First, there are expected diversification of methods of supplying rental homes and houses. This means that houses and homes will not only be limited to buying and building but also more projects that will serve different needs of people who looking for houses to rent and those seeking to be homeowners. This will be made possible through a flexible NHUF operation where the rates can be paid in flexible charges with fewer interests. Secondly, there are expected changes in the improvement of the housing environment. For instance, there will be small size housing plans through the introduction of private houses that will be easier to finance and construct. More importantly, the funds are expected to improve the landscaping of commercial facilities to serve the residents and neighboring communities effectively. Through this, the economy is boosted, standards of living improved and urban regeneration progressed (Park et al).

\section{National Housing and Urban Fund (NHUF)}

The National Housing and Urban Fund (NHUF) in South Korea came about as a way of speeding urban regeneration through and offering affordable housing to netizens. This was made possible through advanced technology, social innovation and community outreach. Through this, urban planning laws were revised and better, influential and more achievable guidelines and goals enacted to pave way for the growth of the same. Its main role was to deliver stable housing to people while giving cities and urban areas a new life with a view of improving lives through quality housing. NHUF operates on five techniques which are Targeting cities and urban towns, offering support through loans and diversified investment methods, government budget, financing consumers and exclusive operation institutions. The fund ideally allows private development (Sohn et al, 2020). Rapid and increased population leads to high crime rates due to unemployment and limited resources. In South Korea for instance, there are high crime rates in cities and urban areas, hence estate and housing management are very essential. This management comes in different packages such as a working security system and security personnel who are employed to man and secure different houses and apartments (Lee et al, 2019). A foreign investor can buy a house/ invest in the construction of one where the property will be well managed and services while ideally ensuring that the investor is well cushioned from losses, destruction and high-interest rates accrued by lands. This is a major milestone after the war since a good number of South Koreans who were immigrants 
could not be able to afford the same. The majority of South Koreans who had migrated from their country and those who had been taken to Japan as slaves started to move back home. Owned houses and started housing projects. Some who lived in shanties and buildings that were constructed illegally are now able to afford land under the NHUF scheme thus meeting their housing needs.

\section{Real Estate}

According to a new study, housing and real estate prices has become a bigger threat than politics (Jeon, 2019). Apparently, real estate is a very sensitive sector in South Korea detailing land brokers and inflated land prices. It has thus proven very difficult for the government to stabilize the real estate prices and markets, a factor that has hugely impacted the South Korean economy. First, the value of land and real estate continues to rise and thus cannot depreciate regardless of the time it took to construct or build a house. Therefore, with the market diversities, real estate in South Korea has become very valuable with foreign investors paying huge sums of money to have a stake. This is a challenge to locals as the foreign investors are highly competing for this inflating the prices and making the house very expensive to afford.

Generally, Real Estate is very expensive and an investment that can be counted on. However, with brokers and other foreign investors tapping into the market, land prices shoot high and the affordable housing agenda by the State is derailed. The study further revealed that $85 \%$ of South Korea's household wealth in 2019 was in real estate. Therefore, the competition for real estate is very tough with the wealthy continuing to enrich themselves while those living in lower-class struggling to meet their housing needs. Take, for instance, the example of a landlord or an aspiring one. He/she buys a piece of land and wants to invest in real estate. He will construct different housing units and for one to occupy, there is either a full payment to buy the house or monthly installments for the same. For those who want to rent, one will be required to pay a deposit that is most likely refundable during moving out and remit monthly payments for the period that the person will live on the premises. Within a couple of years, the investor who owns the property will have recovered all his money used on the project and will be making more while the one who rented keeps remitting money to the landlord while his/her housing needs are strained. Therefore, housing in South Korea has both advantages and advantages with the wealthy continuing to get rich while the lower class struggling to meet their housing needs. Also, the housing prices in South Korea continue to steadily rise with the majority of homeowners being Koreans investors. The Korean culture ideally promotes owning a home hence the increased prices in real estate. In South Korea, owning a personal home is considered a very important asset to stability in life. Therefore, the culture of looking forward to their own homes has greatly impacted the prices of real estate in South Korea.

South Korea has hugely benefitted from urban regeneration programs as houses have been constructed, developed and refurbished to meet the diversifying tenant changes. The reconstruction of urban regeneration in South Korea began in the 1950s, after the Korean War. This has quickly changed and transformed cities that had been completely destroyed by the war. For instance, buildings that had been brought down have been reconstructed into even better ones and those that survived refurbished to meet the dynamic modernity. In the process, residential homes, infrastructure, building development necessitated the social change.The economy has been boosted through urban regeneration and land use. More important to note is that land use has been redefined through the environmental, socio-economic and health outcomes. Therefore, how a nation is governed plays a key role in land use and urban regeneration through the policies instituted.

\section{Methodology}

Research Design

The study used a mixed method of data collection. Both qualitative and quantitative methods were applied. The researcher preferred to the two methods because they systematically integrate data within a distinct study. The other reason is that the two methods a more complete and strong use of data and information. Using these methods, both types of data was collected at the same time and together they were displayed. The aim was to ensure that there is provision for validity. It also created a concrete basis for development and conclusion. The methods enabled rich field as far the combination of data and figures were concerned so as to add meaning to the interpretation of the numbers. Qualitatively, there was a case study that was used to make use of the in-depth interviews. On the other hand, quantitative involved the use of survey techniques to answer study questions.

The understanding of the knowledge of the territory was based on;

- Organic survey of the daily routine of the living conditions within the major South Korea cities

- Recognition of inhabitants in terms of age, education, gender, income and location

- The nature and history of the place (jurisdiction and administration)

- Local economy; enterprises, foundations, private utilities, collaborative processes among others

- Recognition of the available and accessible services

- Built environment which includes housing survey, bioclimatic survey on the overheating of the outdoor spaces as well as the survey of the architectural envelope and other associated technical transmittances 
- Identification of urban contest as well as the investigation of the relationship that exists between natural environment and settlement environment

\section{Architectural level}

- Identification of the problems to be faced

- Design of public places and allow inhabitants to meet and interact

- Design a technological-morphological innovation by use of minimal intervention on the existing building

- Redesigning of some of the apartment units with the aim of improving the quality of life among the people

\section{Interviews}

Interviewing was used by the researcher to seek for concrete information regarding urban regeneration in South Korea. Semi structured interview questions were formulated based on the research questions. From the formulated questions, the respondents provided the answers during the interview. The semi-structured interviews were made up of key questions helped to define the areas that were to be explored. However, both the researcher and the interviewees were able to diverge to create room for pursuing of and responses in a more detailed manner. Interview as a way of data collection was deemed effective in getting in-depth firsthand information regarding urban regeneration in South Korea cities. The researcher organized for direct interview with a sample of South Korea local community leaders and urban planners to get their feelings regarding urban regeneration. A wealth of narrative information was gathered and the findings were used to come up with credible recommendations and conclusions.

a) Participants sampled
\begin{tabular}{|l|l|l|}
\hline No. & Participant & Total \\
\hline 1 & Urban planners & 10 \\
\hline 2 & Local Authority Leaders & 15 \\
\hline & Total interviewees & $\mathbf{2 5}$ \\
\hline
\end{tabular}

\section{b) Gender Representation}

\begin{tabular}{|l|l|l|}
\hline Men & Ladies & Total \\
\hline 18 & 7 & $\mathbf{2 5}$ \\
\hline
\end{tabular}

Among the interviewees, the male gender was highly represented. Out of the 25 people who were interviewed men were 18 which represented $78 \%$ of the total representation while the female gender was represented by 7 people which was only $22 \%$ of the total representation.

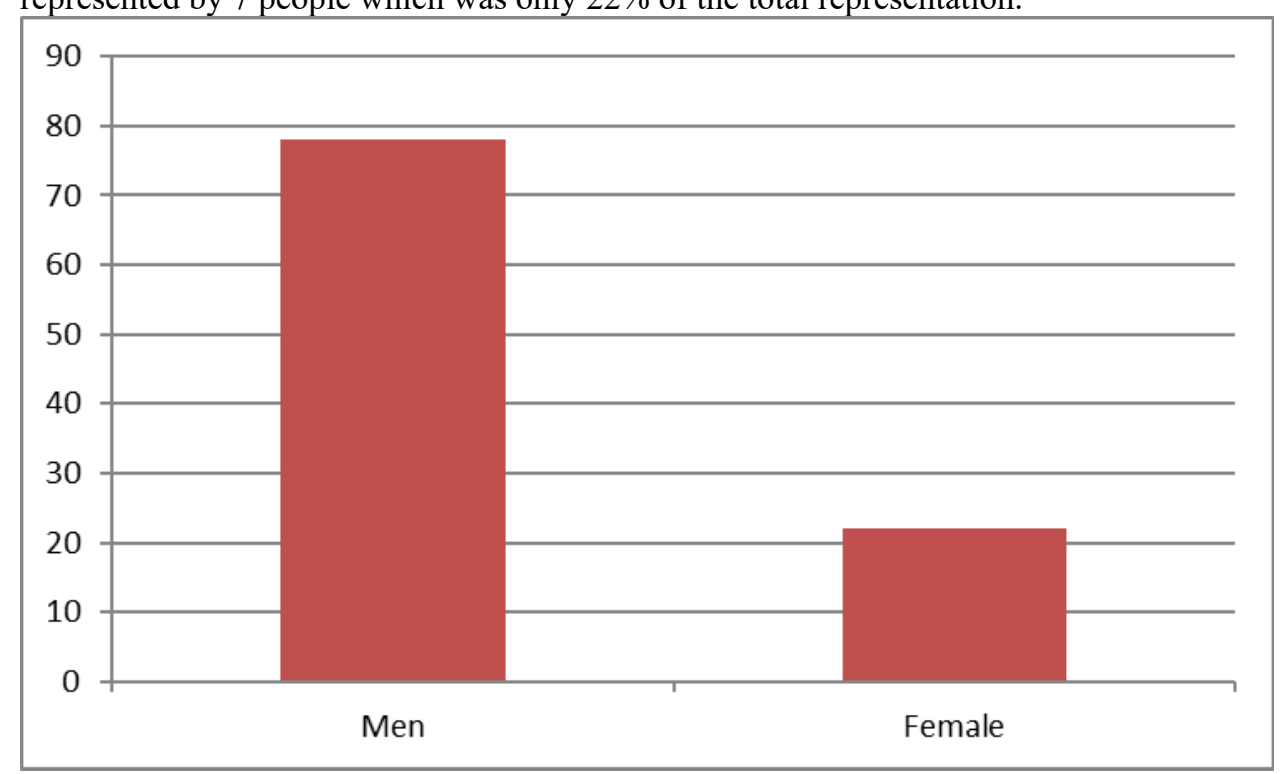

c) Advantages of Urban regeneration

Some of the advantages of urban regeneration that were mentioned by the responded include; helping in reviewing the urban landscape and making desirable changes, restructuring of urban design, it also helps in regenerating civilization and helping improve an overall concept of national identity. 


\begin{tabular}{|l|l|l|}
\hline Advantages of Urban regeneration & Number of times mentioned & \% representation \\
\hline Renewing the urban landscape & 7 & 28 \\
\hline Restructuring urban design & 5 & 20 \\
\hline Regenerating civilization & 3 & 12 \\
\hline Makes an overall concept of national identity & 10 & 40 \\
\hline
\end{tabular}

\section{Graphical representation of the Advantages of Urban regeneration}

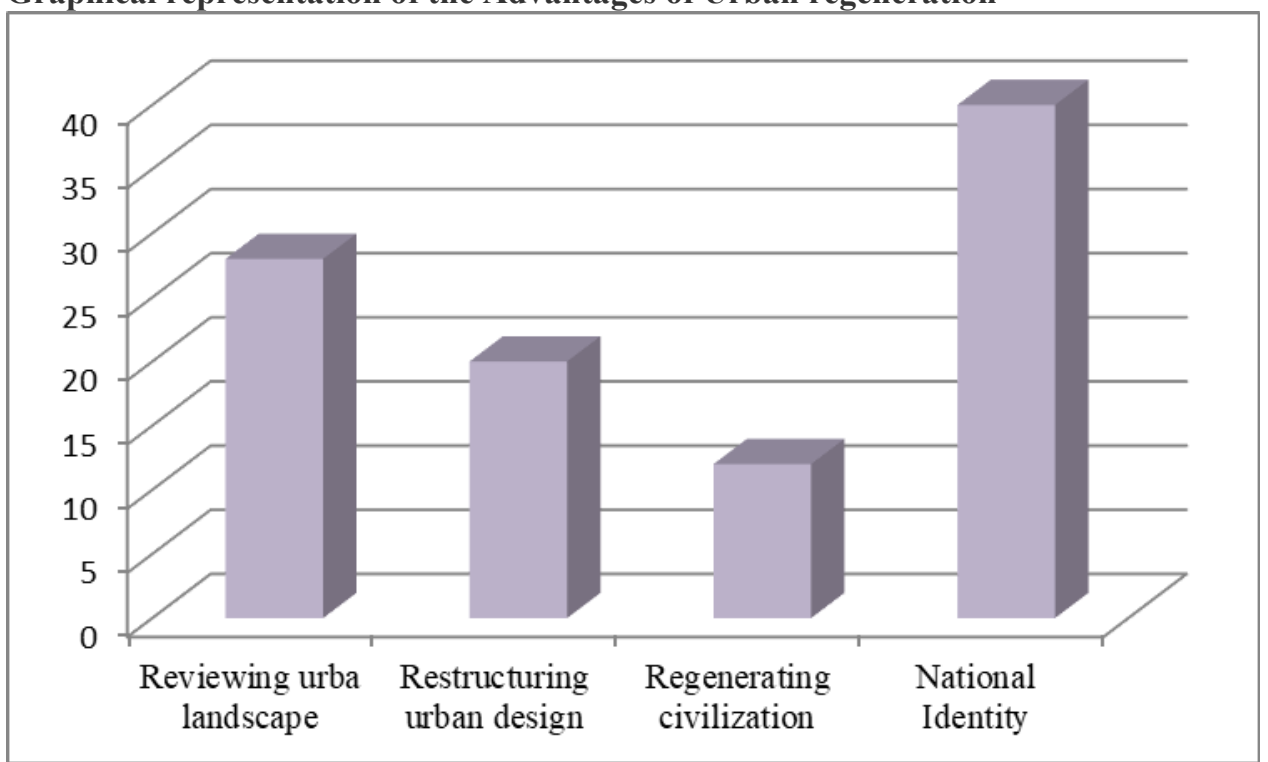

d) Changes that have come about as a result of Urban Regeneration in South Korea

\begin{tabular}{|l|l|}
\hline Changes & \% representation \\
\hline Improved urban environment & 24 \\
\hline Improved urban economy & 36 \\
\hline Improved social context (cohesion, equality) & 16 \\
\hline Improved Urban governance & 24 \\
\hline
\end{tabular}

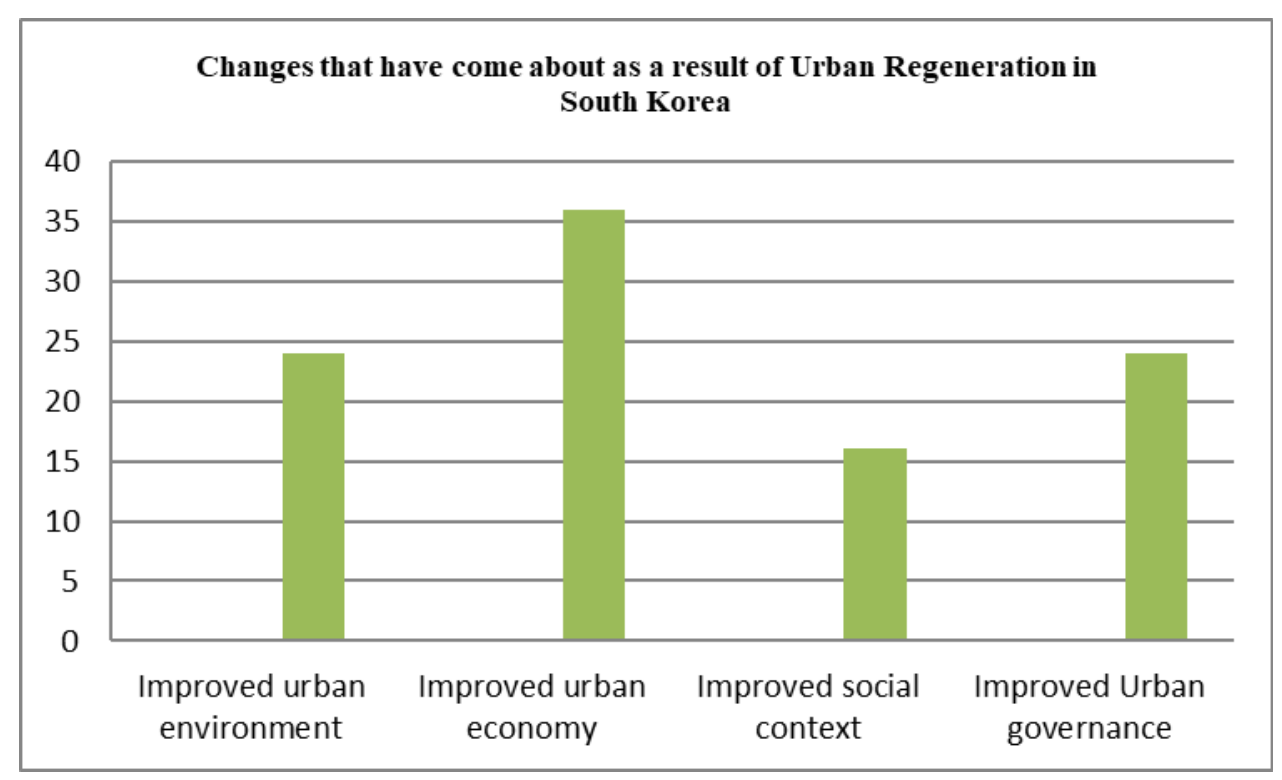




\section{e) Ways of Improving Urban Housing}

\begin{tabular}{|l|l|l|}
\hline Ways of Improving Urban Housing & Participants & $\begin{array}{l}\text { Percentage } \\
\text { representation }\end{array}$ \\
\hline Addressing the issue of affordability & 7 & $28 \%$ \\
\hline Provision of adequate privacy; adequate space; physical accessibility & 8 & $32 \%$ \\
\hline Socially-enhancing and environmentally friendly residential practices & 6 & $24 \%$ \\
\hline $\begin{array}{l}\text { Inclusion of urban planning considerations such as advocating for mixed } \\
\text { urban uses }\end{array}$ & 4 & $16 \%$ \\
\hline
\end{tabular}

\section{Ways of Improving Urban Housing}

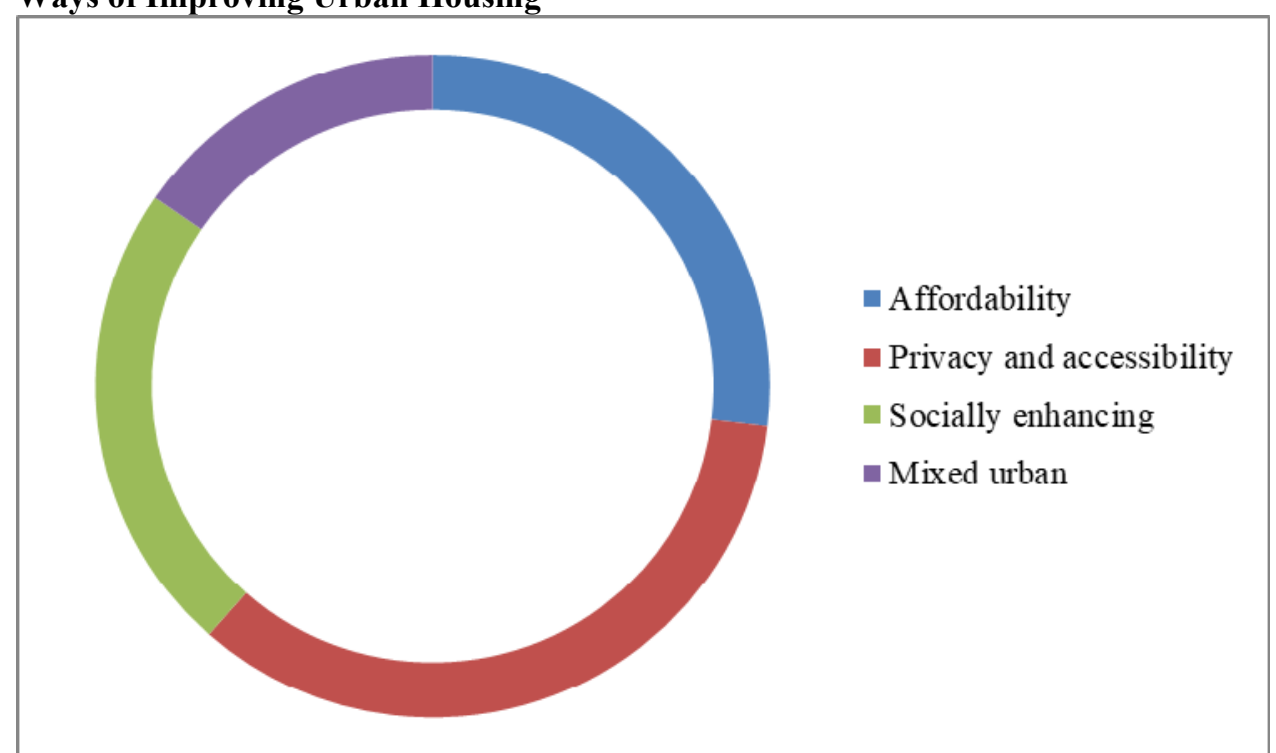

The results were shared with the local population trough a candid discussion. During the discussion, agreements and disagreements were highlighted regarding the descriptive results of the impending problems that were well pointed out through quantitative and the general perception of the locals. The buildings with the city had spokesperson played a crucial role in the recruitment of other stakeholders through the use of personal networks. There was the identification of community leaders and trough the community leaders there were spokespersons who represented the interests of the major buildings.

Qualitative research looked into inhabitants. This was brought out through the use of a social-living survey that was structured by an experienced architect. The aim was to gain an understanding of the perception of the inhabitants as far as the subjective health of the community is concerned in terms of physical, social environments and their personal relationship and interaction with both the local and health institutions. The survey was carried out in a paper based-format. The main topics of the survey included home, leisure, work and mobility. Questions were presented to the interviewees. Open ended questions were used to give the responded with the freedom to express themselves.

\section{Analysis}

This entails the process of making sense out of the collected data. According to Kimet al., (2019), the process involves measuring of the behavior and categorizing the information provided through a meaningful element. In this study, on qualitative data, textual thematic analysis was adopted to identify the forms of themes that were used to get information from the respondents. The themes that were evident were put into category and later on presented so that they tell the story regarding what the respondents of the study answered. Through the use of qualitative data from the research questions, tables and graphs were produced for easy interpretation. The data was then descriptively analyzed and finally summarized to try to bring out the various set of emerging issues.

The researcher worked continuously with territorial regeneration of activities which had dual utilities. The study allowed for the collection of information which was required for the understanding of the territorial identity and the strengthening of development prospects. Through the use of direct survey in conjunction with the local authority, it was easy to find out the views of the stakeholders within the surrounding environment. Direct discussion enabled acquisition of new contacts among the locals, the local government and investors. The process highlighted the significance of urban regeneration through emphasizing the cooperation and coordination of various stakeholders. The process was systematized in three important phases which included;

- Survey listening: The aim of this was to identify the opinions as well as the views of the various 
stakeholders and by doing this; the cognitive framework of the territory was enriched.

- Organizing communication plan so as to make sure that any form of discussion among the stakeholders mainly revolved around the project

- The shared strategies could be elaborated in a more understandable way. The main aim was to highlight solutions to the shared problems identified throughout the process.

\section{Results and Discussion}

The systematic reading of the regulatory plan indicated a clear divide between the central urban areas found within the municipality and the marginal that are not found within the municipality. The results indicate that from the center of the city moving outwards, the good conditions tend to slowly fade, creating room for deteriorated areas. There is also a difference based on the characteristics of the population of the cities concerned. The distribution is also based on the level of education. A higher percentage represents elementary qualifications or those without degree while lower percentages of inhabitant represent those with high levels of qualifications. The differences are accentuated as one moves from the outskirts towards the center of the cities. The percentage of unemployed is greater outside compared to those living within the city centers.

The nature of the settlement is highlighted by the inequalities experienced through four different types of cities. They include historical city, consolidated city, renovated city and city to be transformed. Historical and consolidated cities are saturated and are also parts of the metropolis. The second two are parts of the city that require some renovation to be carried out. As far as the environmental system is concerned and the infrastructural services, the data refer to the macro areas of greenery, urban services like hospitals and universities and big infrastructures like railway system. The Greenfield represents public domain. The mapping of services within the major city centers is a clear indication that public services are not easy to get by.

\section{Conclusion}

In conclusion, it is evident that for successful urban regeneration in South Korea, the element of planning such as sustainability, urban simulation, and local identity need to be put into consideration in areas where regeneration has to be carried out. The paradigm that has emerged based on the demands of each age is determined according to the level of acceptance as well as the executions of the demands of the prevailing circumstances and time. The manner in which regeneration is realized in each region should always be diverse. The strategy of urban regeneration should therefore be considered in South Korea. South Korea should be focused in the development of online platforms that are meant to encourage participation of the various stakeholders of the economy. Technology-based techniques will become sources of countless supply of new ideas that are also likely to gain from popular approval for their ability to bring changes into the community. Real change and improvement in the sector is likely to be made when citizen start gathering together to socialize. The future potential of South Korean cities is something that should be welcomed by citizens. The dream must be shaped together through participation and fruitful engagement.

\section{Recommendations}

Urban regeneration is a collaboration process that entails a number of actors and stakeholders. From the study, it is evident that successful urban regeneration is nolonger a top-down exercise engineered by the state but a partnership between the government and the broader coalition of various institutions and actors. Systems that have been put in place to facilitate urban regeneration need to be tuned to enable them respond to the challenges that are associated with growth. South Korean government has put in place a strong system at strategically important sites through the urban regeneration actors such as Korean Housing and Urban Guarantee Corporation. Private sectors as well as the civil society have also played a great role in actualizing urban regeneration programs.

There is need for South Korean cities to have multi-stakeholder systems to be able to adequately prepare and market their economy both locally and globally. Agencies need to collaborate to be able to develop and promote and develop the country. There is need of bringing significant sites to market to be able to attract skilled workers and possible and viable investments programmes that aim at revamping the economy of most South Korean cities. Provision of insights for South Korea cities need to be the new institutions and the collaborative formats that are coming up in some of the cities spear-headed by the long term funding of the government. The long term funding programme can easily support regeneration, infrastructure as well as the creation of jobs. The metropolitan government of the major cities of South Korea can come up with ways of coordinating the operations of the programmes. For the region to meet its ambitions of creating a highly skilled and inclusive and entrepreneurial workforce there is need for collaboration with other stakeholders to ensure that the objectives of the city are attained. The mandated bodies could review the eco-system in which the future urban regeneration strategy exists and be able to examine whether all pillars of the laid out strategies can be operationalized based on the available structures. The infrastructure as well as human capital can help in shaping an all-inclusive 
economy within the major cities in South Korea. The long-term funding package brings about a long-term certainty into the development process. The urban cities in South Korea have benefitted from the strong local leadership that has played a great role in shaping the approach to regeneration that has taken place in the city and brought about the shift from intervention that are development-oriented to the people-centered initiatives. The approach should then be embedded into the national framework so that it creates opportunities to build new coalitions in the South Korea cities to push the projects forward.

The national government should be able to recognize the significance of the local communities in the process of urban regeneration. New projects require building of new capacity among the local communities and walk together with the stakeholders as well as the beneficiaries in determining the resultant outcomes. By doing this, a platform for civil leadership will be created which focuses on the basic needs of the surrounding due to the loyalty and civic identity. Through involving civic leadership, the right projects will be identified based on the needs and aspirations of the locals. The local leaders engage the local government. Consequently, they are able to build consensus amongst the stakeholders.

\section{Disclosure statement}

No competing financial interests exist.

\section{Funding}

No funding was received

\section{References}

Wolfram, M. (2019). Assessing transformative capacity for sustainable urban regeneration: A comparative study of three South Korean cities. Ambio, 48(5), 478-493.

Seo, B. K., \&Joo, Y. M. (2019). Innovation or episodes? Multi-scalar analysis of governance change in urban regeneration policy in South Korea. Cities, 92, 27-35.

Yoon, H. (2017). Transforming the economic value of hillside housing-A case study of Seoul, South Korea. Urban forestry \& urban greening, 24, 35-44.

Ham, S., \& Lee, H. (2017). Topological Transitions in Collective Housing Units of South Korea. Sustainability, $9(1), 31$

Watt, P., \&Smets, P. (Eds.). (2017). Social housing and urban renewal: A cross-national perspective. Emerald Group Publishing.

Park, J. H., Yu, J. S., \&Geem, Z. W. (2018). Genetic algorithm-based optimal investment scheduling for public rental housing projects in South Korea. International Journal of Fuzzy Logic and Intelligent Systems, 18(2), $135-145$.

Kim, S., Lee, S., \& Han Ahn, Y. (2019). Evaluating housing maintenance costs with loss-distribution approach in South Korean apartment housing. Journal of Management in Engineering, 35(2), 04018062.

Jang, H., Song, Y., \&Ahn, K. (2020). Can government stabilize the housing market? The evidence from South Korea. Physica A: Statistical Mechanics and its Applications, 124114.

Kim, K. H., Jeon, S. S., Irakoze, A., \& Son, K. Y. (2020). A Study of the Green Building Benefits in Apartment Buildings According to Real Estate Prices: Case of Non-Capital Areas in South Korea. Sustainability, 12(6), 2206

Kim, M. (2018). Urban Middle-Class and the Politics of Home Ownership in South Korea. Development and Society, 47(4), 503-534.

Kang, J. W., Lee, Y. C., Han, K., Kim, S. W., \& Lee, K. H. (2020). Epidemiology of anosmia in South Korea: a nationwide population-based study. Scientific Reports, 10(1), 1-8.

Sohn, D. W., \&Ahn, Y. J. (2020). Does spatial configuration matter in residents' conflicts in public housing complexes? Evidence from mixed tenure housings in South Korea. Journal of Asian Architecture and Building Engineering.

Lina, \&Beanseon(2019). Analysis of Urban Housing Policies for Low-Income Households in Colombia and South Korea: Housing for Social Welfare and Economic Development

(Doctoral dissertation.

Lee, I., Jung, S., Lee, J., \& Macdonald, E. (2019). Street crime prediction model based on the physical characteristics of a streetscape: Analysis of streets in low-rise housing areas in South Korea. Environment and Planning B: Urban Analytics and City Science, 46(5), 862-879.

Jeon, J. S. (2019). How housing market responds to greenbelt relaxation: Case of Seoul Metropolitan Area, South Korea. Land Use Policy, 84, 328-334. 